\title{
ИССЛЕДОВАНИЕ УРОВНЯ ДВУНИТЕВЫХ РАЗРЫВОВ ДНК И МЕХАНИЗМОВ КЛЕТОЧНОЙ ГИБЕЛИ ПРИ ВОЗДЕЙСТВИИ НА КЛЕТКИ РАКА ЛЕГКОГО И МЕЛАНОМЫ ФОТОННОГО ИЗЛУЧЕНИЯ СВЕРХВЫСОКОЙ МОЩНОСТИ
}

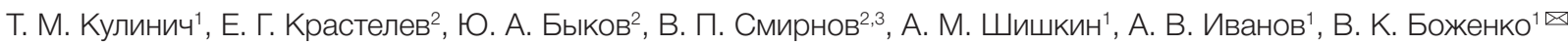 \\ Российский научный центр рентгенорадиологии, Москва \\ Объединенный институт высоких температур Российской академии наук, Москва \\ АО «Научно-исследовательский институт технической физики и автоматизации» Госкорпорации «Росатом», Москва
}

\begin{abstract}
Изучение влияния фотонного излучения сверхвысокой мощности (мощность дозы > $1 \times 10^{7}$ Гр/мин) на биологические объекты является новым и перспективным направлением радиобоиологии. Экспериментальная установка «МИР-М» обладает уникальными характеристиками, позволяющими проводить на ней медико-биологические эксперименты и изучать влияние терапевтических доз при интенсивности дозы до 100 МГр/с. Целью работы было исследовать влияние фотонного излучения сверхвысокой мощности на клетки опухолевых линий рака легкого (А549) и меланомы (MelMtp-x), провести сравнение полученных эффектов с воздействием на клетки излучения терапевтической гаммаустановки «Рокус-АМ». Показано, что излучение сверхвысокой мощности имеет большее повреждающее воздействие на клетки исследуемых опухолевых линий в диапазоне доз от 2 до 7 Гр, при этом радиорезистентная линия меланомы более чувствительна к фотонному излучению сверхвысокой мощности.
\end{abstract}

Ключевые слова: фотонное излучение, гамма-излучение, рентгеновское излучение, сверхвысокая мощность дозы, апоптоз, двунитевые разрывы ДНК

Финансирование: работа выполнена при поддержке гранта Российского научного фонда 15-10355.

$\longrightarrow$ Для корреспонденции: Владимир Константинович Боженко ул. Профсоюзная, д. 86, г. Москва, 117997; vbojenko@mail.ru Статья получена: 15.08.2018 Статья принята к печати: 28.11.2018 DOI: $10.24075 /$ vrgmu.2018.066

\section{INVESTIGATION OF THE LEVEL OF DNA DOUBLE-STRAND BREAKS AND MECHANISMS OF CELL DEATH UNDER IRRADIATION OF LUNG CANCER AND MELANOMA CELLS WITH ULTRA-HIGH DOSE RATE PHOTON RADIATION}

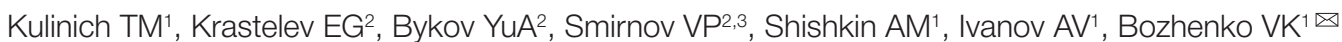

${ }^{1}$ Russian Research Center of Roentgenradiology of the Ministry of Healthcare of the Russian Federation, Moscow

2 Joint Institute for High Temperatures of the Russian Academy of Sciences, Moscow

${ }^{3}$ Research Institute of Technical Physics and Automation of Rosatom, Moscow

Research into the effects of radiation delivered at ultrahigh dose rates $>1 \times 10^{7} \mathrm{~Gy} / \mathrm{min}$ to biological objects is a new promising area of radiobiology. The unique characteristics of the high-current nanosecond electron accelerator Mir-M enable its use in medical and biological research, specifically in the experiments aimed at investigating the effect of therapeutic doses at a dose rate up to $100 \mathrm{MGy/s}$. In this work we study the effects of ultrahigh dose rate photon radiation on human lung carcinoma (A549) and melanoma (MelMtp-x) cells lines and compare them with those of the therapeutic gamma unit Rokus-AM. We show that ultrahigh dose rates induce more significant damage in the studied cell lines at doses between 2 and 7 Gy, radioresistant melanoma being more sensitive to photon radiation delivered at ultrahigh dose rates.

Keywords: photon radiation, gamma radiation, X-rays, ultrahigh dose rate, apoptosis, DNA double strand breaks Funding: this work was supported by the Russian Science Foundation (Project 15-10355).

$\triangle$ Correspondence should be addressed: Vladimir K. Bojenko

Profsoyuznaya 86, Moscow, 117997; vbojenko@mail.ru

Received: 15.08.2018 Accepted: 28.11.2018

DOI: $10.24075 /$ brsmu.2018.066

Лучевая терапия, наряду с хирургическими методами и химиотерапией, занимает одно из главных мест в лечении злокачественных опухолей. В настоящее время повышенное внимание уделяется вопросам индивидуальной радиочувствительности пациентов и выбору тактики лучевой терапии [1-3]. Одним из возможных путей повышения эффективности и в то же время снижения побочных эфффектов лучевой терапии является использование излучения высокой мощности. Однако в литературе имеются данные как об отсутствии биологических эффектов, так и о более глубоком повреждающем воздействии при увеличении мощности дозы [4-7]. Ранее, в исследованиях in vitro, мы показали, что воздействие фотонного излучения с мощностью дозы 109 Гр/с на лимфоциты 
периферической крови человека [8] имеет ряд отличий, по сравнению с излучением с мощностью дозы, применяемой в традиционной лучевой терапии. Полученные различия позволяют высказаться о возможных преимуществах высокомощностного фотонного излучения с точки зрения как терапевтического диапазона, так и более благоприятных для организма механизмов радиационного повреждения. Использование методики облучения фотонным излучением сверхвысокой мощности, возможно, позволит внести новые элементы в лечение онкологических заболеваний.

Целью исследования было определить особенности воздействия фотонного излучения экспериментальной установки МИР-М сверхвысокой мощности на клетки опухолевых линий человека in vitro.

\section{МАТЕРИАЛЫ И МЕТОДЫ}

Источником фотонного пучка ультравысокой мощности служила экспериментальная установка «МИР-М», созданная на базе ФГБУ Объединенный институт высоких температур РАН (Москва). Мощность дозы высокоинтенсивного излучения установки «МИР-М» лежала в интервале $1-4 \times 10^{9}$ Гр/мин. В качестве источника излучения с мощностью дозы, традиционно назначаемой для лучевой терапии злокачественных опухолей, использовали гамматерапевтический аппарат «Рокус-АМ» с источником излучения кобальт-60 (Со-60). Мощность дозы облучения на аппарате «Рокус-АМ» составляла около 1 Гр/мин.
В качестве биологических моделей для исследования эфффектов облучения in vitro использовали культуры клеток линий MelMtp-x (меланома человека; коллекция ФГБУ «НМИЦ онкологии им. Н. Н. Блохина»; Россия) и клетки линии A549 (аденокарцинома легкого человека; коллекция Cell Lines Service (Human Lung Carcinoma 300114); Германия). Для обоих типов облучения исследовали цитотоксические эффекты (общее количество погибших клеток, уровни апоптоза и некроза) и влияние облучения на уровень двунитевых разрывов (ДНР) ДНК.

Разморозку и культивирование клеточных культур проводили стандартными методами с использованием сред DMEM для A549 (ПанЭко; Россия) и RPMI 1640 (Gibco; США) для MelMtp-х, содержащих 10\%-ю эмбриональную телячью сыворотку (BioWest № S1800; Франция).

Облучение образцов на установке «МИР-М» и терапевтической гамма-установке «Рокус-АМ» производили по описанным ранее методикам [8]. Цитосрлуорометрический анализ проводили на проточном цитосрлуориметре (Beckman Coulter; CША).

Количество ДНР ДНК оценивали по уровню фосфорилирированного гистона Н2А.X согласно методике производителя с помощью набора 17-344 Н2А.X Phosphorylation Assay Kit (for Flow Cytometry) (Millipore; CША).

Исследование путей гибели клеток в образцах, подвергшихся облучению, проводили через 24 и 48 ч после воздействия с использованием набора Annexin V-FITC Kit (Beckman Coulter; CША), содержащего аннексин V

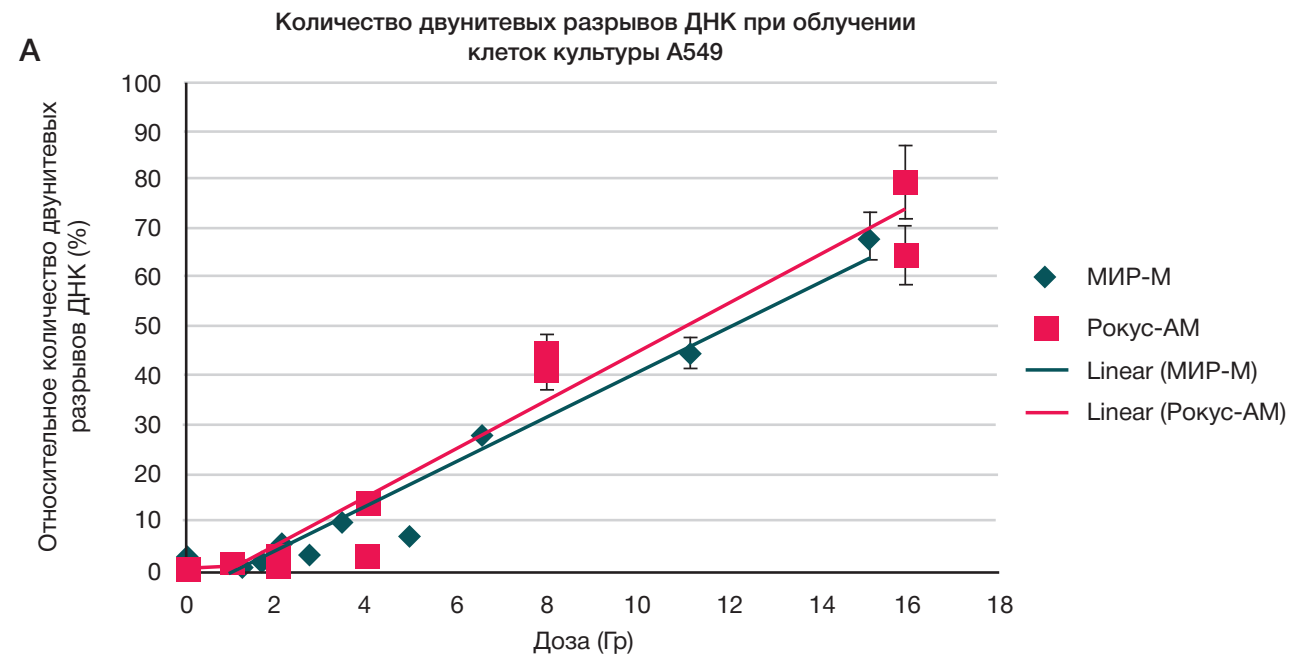

Б

Количество двунитевых разрывов ДНК при облучении клеток культуры Mel Mtp-х

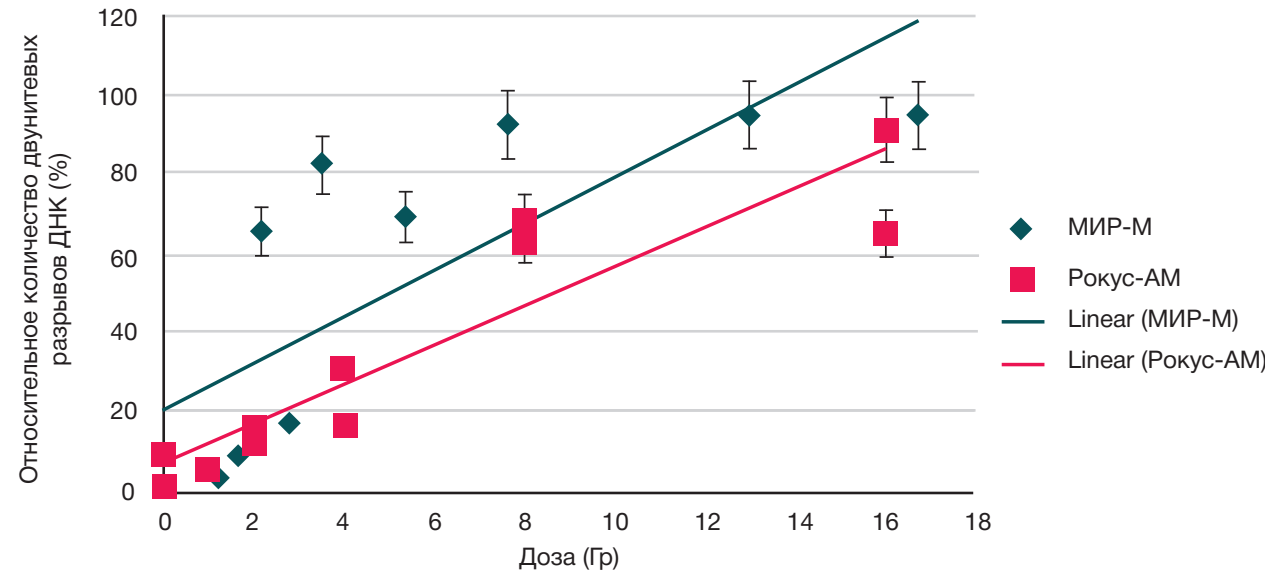

Рис. 1. Изменение уровней двунитевых разрывов ДНК в культурах A549 (A) и MelMtp-х (Б) после воздействия гамма-излучения терапевтической установки «Рокус-АМ» и экспериментальной установки высокоинтенсивного рентгеновского излучения «МИР-М» 
и йодид пропидия, позволяющего одновременно провести оценку уровня апоптоза и некроза [8]. Оценку статистической достоверности различий проводили на основании критерия Стьюдента. Достоверными считались различия при $p<0,1$.

\section{РЕЗУЛЬТАТЫ ИССЛЕДОВАНИЯ}

Анализ изменений количества ДНР ДНК в культуре А549 (аденокарцинома легкого) (рис. 1А) показал, что для двух типов излучения достоверных различий нет. В то же время для культуры MelMtp-х обнаружено, что если зависимость «доза-эффект» при воздействии гамма-терапевтической установки «Рокус-АМ» имеет линейный вид, зависимость уровня ДНР при воздействии «МИР-М» носит нелинейный характер (рис. 1Б). При воздействии фотонного излучения сверхвысокой мощности в культуре MelMtp-х наблюдали резкое увеличение количества ДНР в диапазоне доз 2-5 Гр (65,7-80\%) (p<0,1). При дозах более 7 Гр уровни ДНР для двух типов излучения достоверно не различались и достигали максимальных значений 95\%.

Анализ количества погибших клеток показал некоторые различия, связанные, по-видимому, как с типом воздействия на клетки, так и с особенностями исследуемых культур (рис. 2). При облучении клеток линии А549 с помощью установки «Рокус-АМ» было показано, что 24-часовая инкубация после облучения не приводит к значимому увеличению количества погибших клеток, количество позитивных по красителю РІ (йодид пропидия) клеток не превышало 6\% (рис. 2А). Однако увеличение времени инкубации после облучения до 48 ч сопровождается достоверным увеличением числа погибших клеток до 32,6\% при 8 Гр и 41,2\% при 16 Гр. При облучении клеток MelMtp-x на экспериментальной установке «МИР-М» и временем инкубации 24 ч получены достоверные отличия в уровне позитивных по РІ клеток, как с контрольными необлученными образцами, так и с образцами, подвергшимися облучению на «РокусAМ» (рис. 2Б). Значимое увеличение доли погибших клеток наблюдалось уже при дозах от 1,4 Гр (14,8\%) и достигало наибольших значений при дозе 11,7 Гр (31,2\%). В то же время увеличение времени инкубации до 48 ч не приводило к значимому увеличению числа мертвых клеток в образцах, облученных на «МИР-М». Отмечено также, что при инкубации 48 ч отсутствуют достоверные различия между количеством погибших клеток при сравнении двух типов излучения.

Для культуры MelMtp-х было показано, что воздействие гамма-терапевтической установки не приводит $\mathrm{k}$ увеличению погибших клеток более чем на 7\%, время инкубации не влияет на клеточную гибель. Воздействие установки «МИР-М» и инкубация 24 ч также не дают значимых эффектов, но увеличение времени инкубации до 48 ч приводит к резкому возрастанию доли мертвых

A

Изменение количества мертвых клеток в культуре А549
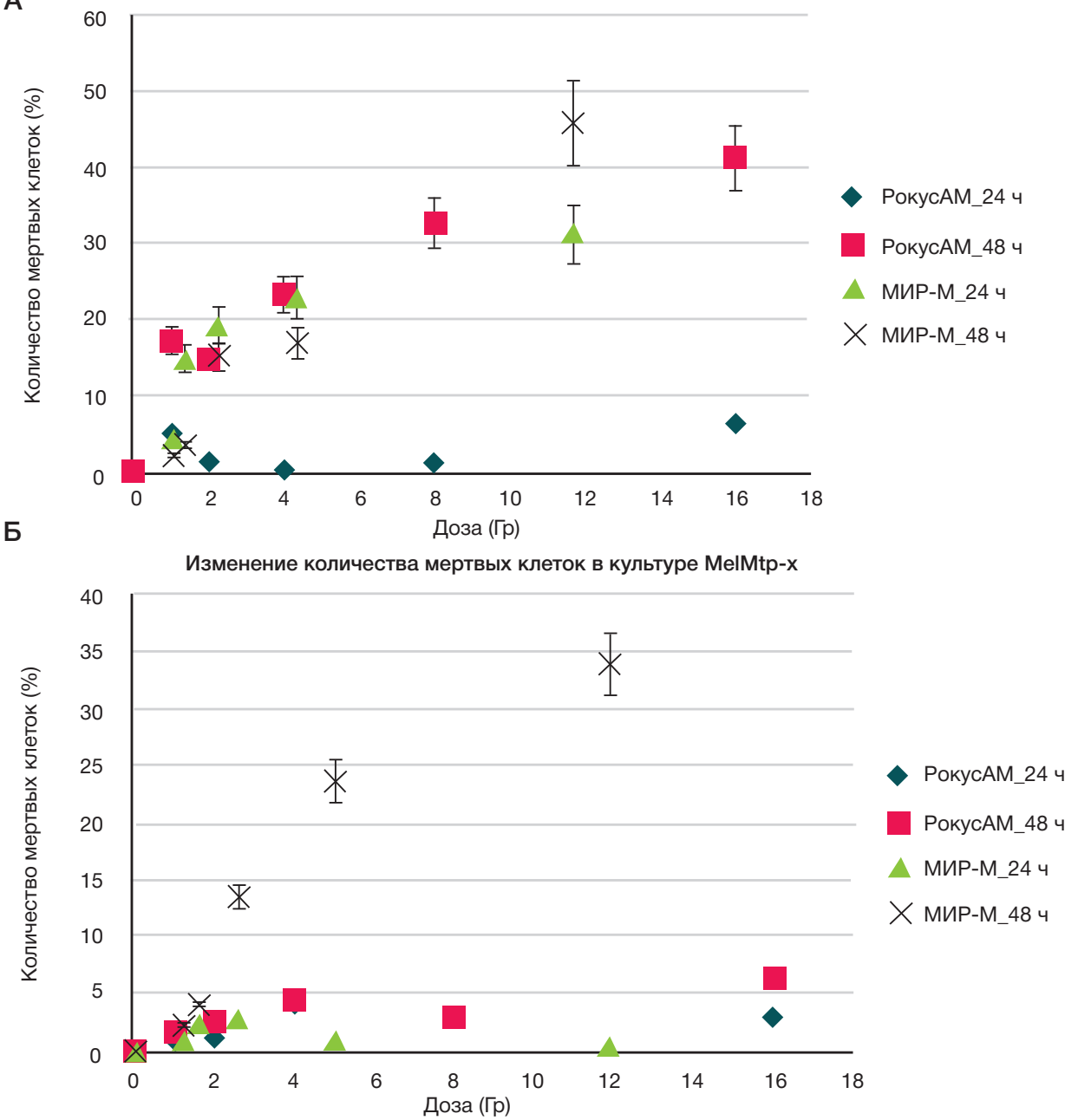

Рис. 2. Изменение количества погибших клеток в культурах A549 (А) и MelMtp-х (Б) после воздействия гамма-излучения терапевтической установки «РокусAM» и экспериментальной установки высокоинтенсивного рентгеновского излучения «МИР-М» 
клеток в образцах: при дозе 2,5 Гр количество мертвых клеток составляет 13,4\%, при дозе 11,8 Гр - 33,8\%.

Исследование типов клеточной гибели показало, что больший вклад вносит механизм гибели клеток по пути апоптоза (рис. 3). Для клеточной линии А549 значимые отличия в уровне апоптоза, индуцированного высокомощным излучением, по сравнению с гамматерапевтическим, наблюдались в дозах от 1,4 Гр при инкубации клеток 24 ч (рис. 3А). При увеличении времени инкубации до 48 ч различия между двумя типами воздействия нивелировались. Однако увеличение уровня апоптоза как для «Рокус-АМ», так и для «МИР-М», было достоверно: при воздействии на клетки фотонным излучением сверхвысокой мощности в дозе 11,7 Гр уровень апоптоза в культуре А549 составил после 24-часовой инкубации 21,4 \pm 3,2\% и 43,0 \pm 5,2\% после 48-часовой инкубации. После облучения установкой «Рокус-АМ» в дозе 16 Гр и времени инкубации 24 ч уровень апоптоза в культуре составлял 4,8 \pm 0,7; при увеличении времени инкубации до 48 ч он возрастал до $38,4 \pm 4,6 \%$.

Для клеточной линии MelMtp-х апоптоз, индуцированный воздействием гамма-терапевтической установки «РокусAM», не превышал 4\%, увеличение времени инкубации не влияло на его уровень. Воздействие на клетки MelMtp-х установкой «МИР-М» в дозах от 5 Гр после 48-часовой инкубации приводило к достоверному росту уровня апоптоза (рис. 3Б).

Значимые изменения В уровне некроза, индуцированного воздействием «МИР-М», для А549 наблюдались в дозах 4,3 и 11,7 Гр при 24-часовой инкубации (рис. 4А). Количество некротических частиц от общего числа погибших клеток составило 38,6\% для дозы 4,3 Гр и 30,6\% для дозы 11,7 Гр и снижалось до $7,1 \%$ и 6,1\% соответственно при увеличении времени инкубации до 48 ч. Можно предположить, что в культуре А549 некротические клетки эллиминируются в течение двух суток, а процессы апоптоза, индуцированного воздействием высокоинтенсивного рентгеновского излучения, продолжаются.

При исследовании изменения уровня некроза в культуре MelMtp-х было показано, что при времени инкубации 24 ч для обоих типов облучения уровень некроза значимо не повышается (рис. 4Б). При увеличении инкубации до 48 ч уровень некроза возрастал в образцах, подвергшихся облучению на установке «МИР-М» в дозах от 1,58 Гр. Так, при дозе облучения 2,6 Гр он определялся как 8,9 \pm 1,07\% и составлял $66,4 \%$ от общей клеточной гибели; при дозе 11,8 Гр возрастал до $17,5 \pm 2,1 \%$ (51,8\% от общей клеточной гибели).

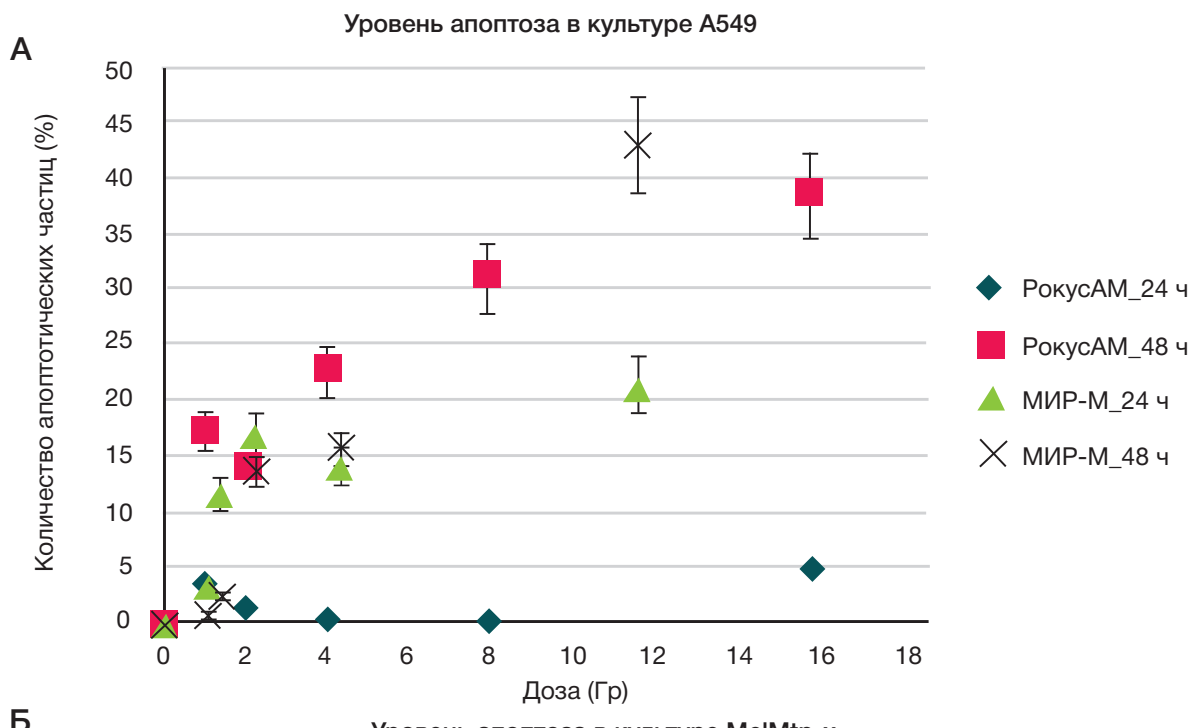

Б

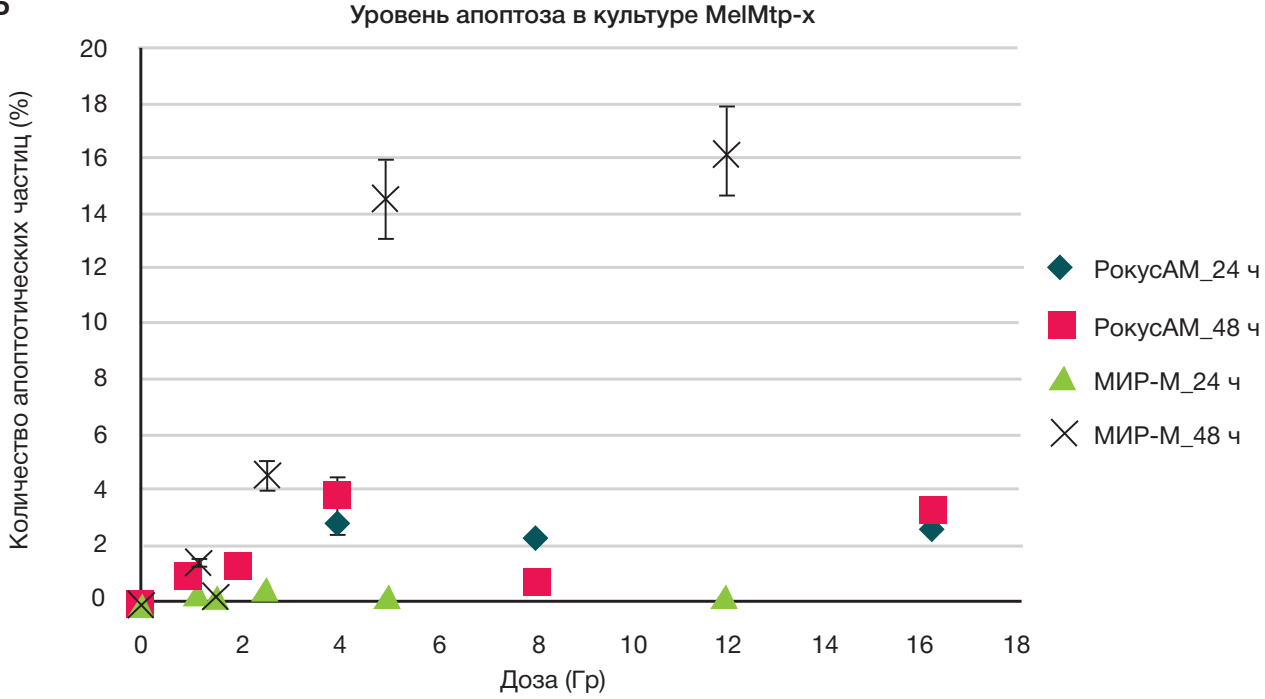

Рис. 3. Изменение уровня апоптоза в культурах A549 (А) и MelMtp-х (Б) после воздействия гамма-излучения терапевтической установки «Рокус-АМ» и экспериментальной установки высокоинтенсивного рентгеновского излучения «МИР-М»; окраска: аннексин V - йодид пропидия 


\section{ОБСУЖДЕНИЕ РЕЗУЛЬТАТОВ}

В проведенных исследованиях было показано, что для двух клеточных линий злокачественных опухолей человека A549 (аденокарцинома легкого) и MelMtp-х (меланома) уровень клеточной гибели выше при воздействии фотонного излучения экспериментальной установки «МИР-М», хотя количество индуцированных ДНР ДНК сопоставимо. Для линии A549 определен значимо более высокий уровень апоптоза при воздействии «МИР-М».

Уровень радиоиндуцированных ДНР характеризует повреждающую способность излучения и во многом определяет дальнейшую судьбу клетки [9]. Ответом клетки является активация процессов репарации ДНК, а также запуск программы апоптоза при невозможности восстановления целостности ДНК. Нарушение на любом из этапов репарации ДНР ДНК приводит к образованию хромосомных аберраций, а в дальнейшем гибели клеток [10].

Количество ДНР, регистрируемое в условиях описанного эксперимента, в первую очередь, определяется параметрами излучения и состоянием систем репарации клеток. Полученные нами зависимости уровня ДНР ДНК от типа облучения для культуры А549 практически идентичны и имеют линейный вид, что может свидетельствовать как о сопоставимой силе повреждающего действия излучения установки МИР-М и гамма-излучения терапевтической установки «Рокус-АМ», так и о сохранности систем репарации ДНР в клетках этой линии. Исследование гибели клеток в культуре А549 в зависимости от типа облучения показало, что высомощностное излучение индуцирует запуск процессов апоптоза через 24 ч после воздействия, в то время как терапевтическое гамма-излучение только через 48 ч. Можно предположить, что повреждения, вызываемые «Рокус-АМ», позволяют клеткам реализовать механизмы репарации, в то время как повреждения клеток линии А549 после воздействия «МИР-М» приводят к более раннему выявлению механизмами репарации клетки необратимости повреждений и активации апоптоза уже через 24 ч после облучения. Высокий уровень апоптоза сохраняется и через 48 ч после облучения, в то время как уровень некроза, индуцированного «МИР-М», резко снижается.

Для клеток культуры меланомы MelMtp-х в дозах от 2,15 до 7,6 Гр отмечался достоверно более высокий уровень ДНР при облучении на «МИР-М». Можно предположить, что уже при дозах 2 Гр количество и характер повреждений ДНК в клетке не позволяют системам репарации реализовать свою функцию. Результаты анализа гибели клеток в культуре MelMtp-x согласуются с данными о радиорезистентности меланом [11, 12]; воздействие терапевтической установки практически не индуцирует клеточную гибель, что может

A

Уровень некроза в культуре А549

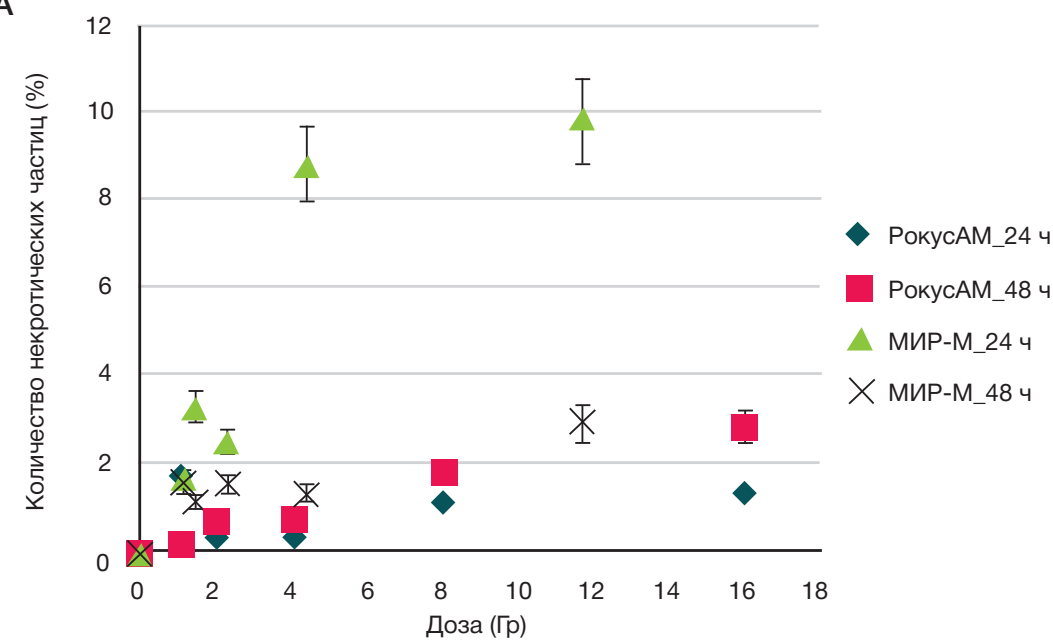

Б

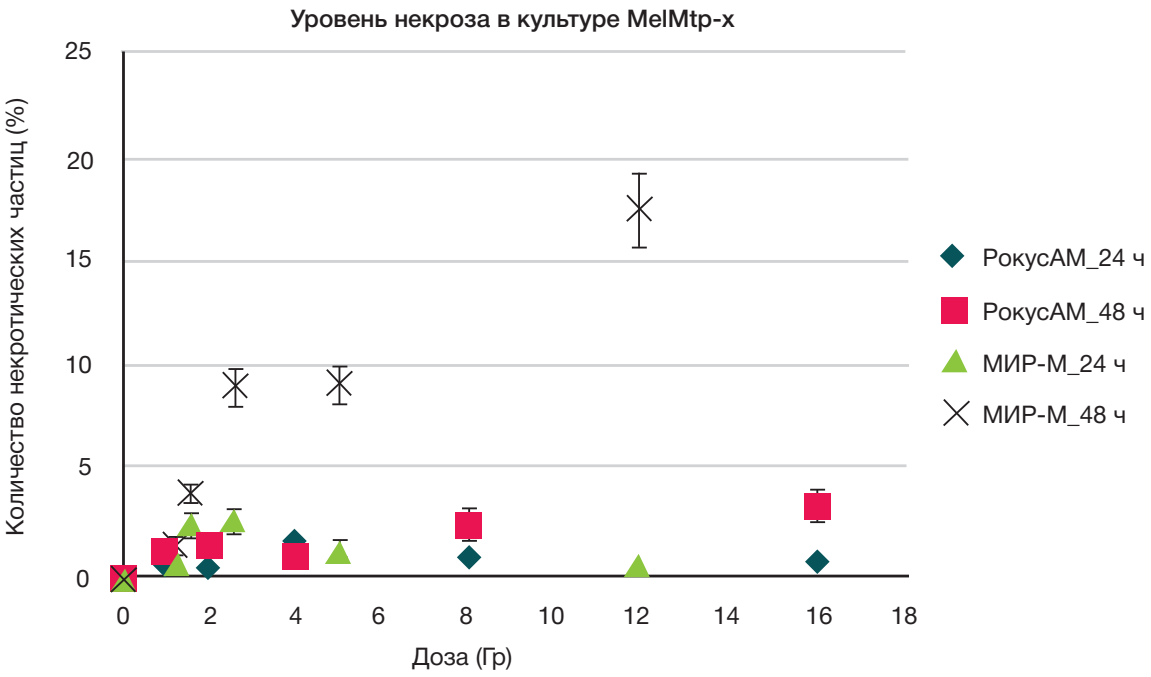

Рис. 4. Изменение уровня некроза в культурах A549 (А) и MelMtp-х (Б) после воздействия гамма-излучения терапевтической установки «Рокус-АМ» и экспериментальной установки высокоинтенсивного рентгеновского излучения «МИР-М»; окраска: аннексин V — йодид пропидия 
свидетельствовать как об отсутствии активации апоптоза на наличие ДНР [13], так и о высоком уровне репарации ДНР [14]. Однако при облучении на «МИР-М» наблюдалась гибель клеток меланомы, причем в тех же дозах (от 2,15 Гр), в которых наблюдалось повышение уровня ДНР. Гибель клеток индуцировалась на вторые сутки после облучения и проходила по пути как апоптоза, так и некроза примерно в одинаковом соотношении. Возможно, воздействие, оказываемое рентгеновским излучением сверхвысокой мощности на клетки меланомы, вызывает необратимые изменения, которые в ряде случаев являются триггером как для запуска апоптоза, так и для индукции гибели клеток по другим механизмам. Таким образом, было показано, что для двух исследованных клеточных линий злокачественных опухолей человека A549 (аденокарцинома легкого) и MelMtp-х (меланома) уровень клеточной гибели выше при воздействии фотонного излучения экспериментальной установки «МИР-М», хотя количество индуцированных ДНР ДНК сопоставимо при использовании максимальных доз. Для линии А549 определен значимо более высокий уровень апоптоза при воздействии излучения «МИР-М».

Перспективность использования излучения сверхвысокой мощности обосновывается в ряде исследований, показаны возможность эффективного воздействия на радиорезистентные опухолевые клетки и минимизация повреждающего воздействия на окружающие ткани при радиотерапии солидных опухолей $[15,16]$.

Результаты по исследованию клеточной гибели при воздействии на радиорезистентные клетки культуры меланомы излучения установки «МИР-М» представляют как практический интерес с точки зрения возможности клинического использования рентгеновского излучения с параметрами мощности дозы, принципиально отличающимися от применяемых в настоящее время, так и интерес с точки зрения изучения особенностей механизмов радиорезистентности и возможности преодоления этих механизмов для лечения радиорезистентных опухолей.

\section{ВЫВОДЫ}

Полученные результаты создают предпосылки для продолжения углубленного изучения влияния фотонного излучения сверхвысокой мощности на биологические объекты. Использование данного типа излучения в терапевтических целях, возможно, позволит повысить эффективность лучевой терапии радиорезистентных опухолей и снизить побочные реакции нормальных тканей.

\section{Литература}

1. Habash M, Bohorquez LC, Kyriakou E, Kron T, Martin OA, Blyth BJ. Clinical and Functional Assays of Radiosensitivity and Radiation-Induced Second Cancer. Cancers (Basel). 2017; 9 (11): 147.

2. Orth M, Lauber K, Niyazi M., Friedl AA, Li M, Belka C, et al. Current concepts in clinical radiation oncology. Radiat Environ Biophys. 2014; 53 (1): 1-29. PubMed PMID: 24141602.

3. Иванов С. Д., Столярова И. В., Ямшанов В. А., Минько Б. А., Белова В. В., Винокуров В. Л. Радиочувствительность ДНК крови как предсказательный показатель эффективности химиолучевой терапии больных раком шейки матки. Вопрось онкологии. 2016; 62 (4): 465-70.

4. Konopacka M, Rogoliński J. Can high dose rates used in cancer radiotherapy change therapeutic effectiveness? Contemp Oncol (Pozn). 2016; 20 (1): 449-52.

5. Slosarek K, Konopacka M, Rogolinski J, Sochanik A. Effect of dose-rate and irradiation geometry on the biological response of normal cells and cancer cells under radiotherapeutic conditions. Mutat Res Genet Toxicol Environ Mutagen. 2014; (773): 14-22.

6. Wang Z, Zhao Z, Lu J, Chen Z, Mao A, Teng G, et al. A comparison of the biological effect of $125 \mathrm{~J}$ seeds continuous low-dose-rate radiation and $60 \mathrm{Co}$ high-dose-rate gamma radiation on non-small cell lung cancer cells. PLoS One 2015; 10 (8): e0133728.

7. Brehwens K, Bajinskis A, Haghdoost S, Wójcik A. Micronucleus frequencies and clonogenic cell survival in TK6 cells exposed to changing dose rates under controlled temperature conditions. Int J Radiat Biol. 2014; (90): 241-7.

8. Грабовский Е. В., Олейник Г. М., Крастелев Е. Г., Смирнов В. П., Хмелевский Е. В., Боженко В. К. и др. Анализ индукции

\section{References}

1. Habash M, Bohorquez LC, Kyriakou E, Kron T, Martin OA, Blyth BJ. Clinical and Functional Assays of Radiosensitivity and Radiation-Induced Second Cancer. Cancers (Basel). 2017; 9 (11): 147.

2. Orth M, Lauber K, Niyazi M., Friedl AA, Li M, Belka C, et al. Current concepts in clinical radiation oncology. Radiat Environ

апоптоза лимфоцитов периферической крови человека сверхинтенсивным гамма-излучением in vitro. Вестник РГМУ. 2017; (6): 59-66.

9. Jackson SP, Bartek J. The DNA-damage response in human biology and disease. Nature. 2009; 461 (7267): 1071-78. DOI: 10.1038/nature08467.

10. Беленко А. А. Цитогенетические и физиологические эффекты гамма-излучения и импульсно-периодического рентгеновского излучения в соматических клетках человека [диссертация]. Томск, 2016.

11. Жуковец А. Г. Современные принципы и перспективы лечения меланомы кожи. Онкологический журнал. 2015; 9 (4): 69-76.

12. Матчук О. Н., Замулаева И. А., Ковалев О. А., Саенко А. С. Механизмы радиорезистентности клеток SP культуры мышиной меланомы В16. Цитология. 2013; 55 (8): 553-9.

13. Tang $L$, Wei F, Wu Y, He Y, Shi L, Xiong F, et al. Role of metabolism in cancer cell radioresistance and radiosensitization methods. J Exp Clin Cancer Res. 2018; (37): 87.

14. Деньгина Н. В., Митин Т. Лучевая терапия у больных с диссеминированной меланомой: паллиатив или стремление к излечению? Новости онкологии. 2018 [19.02.2018]. Доступно по ссылке: https://rosoncoweb.ru/news/oncology/2018/02/19-1/

15. Durante $M$, Bräuer-Krisch $E$, Hill M. Faster and safer? FLASH ultra-high dose rate in radiotherapy. Br J Radiol. 2018; (91):1082.

16. Durante $M$, Orecchia R, Loeffler JS. Charged-particle therapy in cancer: clinical uses and future perspectives. Nat Rev Clin Oncol. 2017 Aug; 14 (8): 483-95. 
4. Konopacka M, Rogoliński J. Can high dose rates used in cancer radiotherapy change therapeutic effectiveness? Contemp Oncol (Pozn). 2016; 20 (1): 449-52.

5. Slosarek K, Konopacka M, Rogolinski J, Sochanik A. Effect of dose-rate and irradiation geometry on the biological response of normal cells and cancer cells under radiotherapeutic conditions. Mutat Res Genet Toxicol Environ Mutagen. 2014; (773): 14-22.

6. Wang Z, Zhao Z, Lu J, Chen Z, Mao A, Teng G, et al. A comparison of the biological effect of $125 \mathrm{~J}$ seeds continuous low-dose-rate radiation and $60 \mathrm{Co}$ high-dose-rate gamma radiation on non-small cell lung cancer cells. PLoS One 2015; 10 (8): e0133728.

7. Brehwens K, Bajinskis A, Haghdoost S, Wójcik A. Micronucleus frequencies and clonogenic cell survival in TK6 cells exposed to changing dose rates under controlled temperature conditions. Int J Radiat Biol. 2014; (90): 241-7.

8. Grabovskij EV, Olejnik GM, Krastelev EG, Smirnov VP, Hmelevskij EV, Bozhenko VK i dr. Analiz indukcii apoptoza limfocitov perifericheskoj krovi cheloveka sverhintensivnym gamma-izlucheniem in vitro. Vestnik RGMU. 2017; (6): 59-66.

9. Jackson SP, Bartek J. The DNA-damage response in human biology and disease. Nature. 2009; 461 (7267): 1071-78. DOI: 10.1038/nature08467.
10. Belenko AA. Citogeneticheskie i fiziologicheskie jeffekty gammaizluchenija i impul'sno-periodicheskogo rentgenovskogo izluchenija v somaticheskih kletkah cheloveka [dissertacija]. Tomsk: 2016.

11. Zhukovec AG. Sovremennye principy i perspektivy lechenija melanomy kozhi. Onkologicheskij zhurnal. 2015; 9 (4): 69-76.

12. Matchuk ON, Zamulaeva IA, Kovalev OA, Saenko AS. Mehanizmy radiorezistentnosti kletok SP kul'tury myshinoj melanomy V16. Citologija. 2013; 55 (8): 553-9.

13. Tang L, Wei F, Wu Y, He Y, Shi L, Xiong F, et al. Role of metabolism in cancer cell radioresistance and radiosensitization methods. J Exp Clin Cancer Res. 2018; (37): 87.

14. Dengina NV, Mitin T. Luchevaja terapija u bol'nyh s disseminirovannoj melanomoj: palliativ ili stremlenie $\mathrm{k}$ izlecheniju? Novosti onkologii. 2018 [19.02.2018]. Dostupno po ssylke: https://rosoncoweb.ru/news/oncology/2018/02/19-1/

15. Durante M, Bräuer-Krisch E, Hill M. Faster and safer? FLASH ultra-high dose rate in radiotherapy. Br J Radiol. 2018; (91):1082.

16. Durante M, Orecchia R, Loeffler JS. Charged-particle therapy in cancer: clinical uses and future perspectives. Nat Rev Clin Oncol. 2017 Aug; 14 (8): 483-95. 